\title{
Investigation of p-dopant diffusion in polymer films and bulk heterojunctions: Stable spatially-confined doping for all-solution processed solar cells
}

\author{
An Dai ${ }^{\mathrm{a}}$, Alan Wan ${ }^{\mathrm{b}}$, Charles Magee ${ }^{\mathrm{b}}$, Yadong Zhang ${ }^{\mathrm{c}}$, Stephen Barlow ${ }^{\mathrm{c}}$, Seth R. Marder ${ }^{\mathrm{c}}$, \\ Antoine Kahn ${ }^{\text {a,* }}$ \\ a Department of Electrical Engineering, Princeton University, Princeton, NJ 08544, USA \\ ${ }^{\mathrm{b}}$ Evans Analytical Group ${ }^{\circledR}$ (EAG), East Windsor, NJ 08520, USA \\ ${ }^{\mathrm{c}}$ Center for Organic Photonics and Electronics and School of Chemistry and Biochemistry, Georgia Institute of Technology, Atlanta, GA 30332-0400, USA
}

\section{A R T I C L E I N F O}

\section{Article history:}

Received 28 January 2015

Received in revised form 7 April 2015

Accepted 23 April 2015

Available online 23 April 2015

\section{Keywords:}

Lamination

Polymer

Doping

Molybdenum complex

Diffusion

\begin{abstract}
A B S T R A C T
The spatial stability of the soluble p-dopant molybdenum tris[1-(methoxycarbonyl)-2-(trifluoromethyl)ethane-1,2-dithiolene] in polymer and polymer blend films is investigated via secondary ion mass spectrometry and current-voltage measurements. Bi-layer and tri-layer model structures, P3HT/doped P3HT and P3HT:ICBA/doped P3HT/P3HT:ICBA respectively, are fabricated using soft-contact transfer lamination to study the diffusion of the dopant. While the dopant is very mobile in pure P3HT, it is far more stable at the interface with the P3HT:ICBA bulk heterojunction. Our findings suggest a promising route to achieve spatially-confined doping with long-term stability, leading to hole-collection/injection contacts for all-solution processed polymer devices.
\end{abstract}

(ㄷ) 2015 Elsevier B.V. All rights reserved.

\section{Introduction}

Electrical doping of organic semiconductors has attracted considerable attention since the early use of alkali metals [1] and alkali metal carboxylates [2] as n-dopants in organic light-emitting diodes in the late 1990s. In the past two decades, progress has been made in understanding fundamental doping mechanisms [3-6], optimizing device performance [7-12], and developing efficient molecular $n$ - and p-dopants [13-17]. A variety of vacuum-processible p-dopants, including tetrafluorotetracyano-quinodimethane ( $\mathrm{F}_{4}$-TCNQ) [3-5,7,10], molybdenum trioxide $\left(\mathrm{MoO}_{3}\right)$ [14], and molybdenum tris-[1,2-bis(trifluoromethyl)ethane-1,2-dithiolene] $\left(\mathrm{Mo}(\mathrm{tfd})_{3}\right)[15]$, and n-dopants, including decamethylcobaltocene $\left(\mathrm{CoCp}_{2}^{*}\right)$ [13], bis(terpyridine)ruthenium (Ru(terpy) $\left.)_{2}\right)[12,18]$ and air-stable dimers of metallocenes and other organometallic sandwich compounds $[6,11,16]$, have been investigated and used in organic devices. Recently, powerful solution-processible molecular $\mathrm{n}$ - and p-dopants have also been developed $[9,17]$, expanding the scope of molecular doping to polymers and solution-deposited small molecules.

\footnotetext{
* Corresponding author.

E-mail address: kahn@princeton.edu (A. Kahn).
}

The present work focuses on the issue of molecular dopant diffusion in polymer films, specifically in structures in which dopants are initially confined in a narrow region of the device. Spatial confinement of dopants is used to enhance carrier injection at an interface without doping the rest of the structure, or to create a built-in potential, for example in a p-i-n device. In our work, dopants are introduced via soft-contact transfer lamination (SCTL) of a separately prepared ultra-thin doped polymer layer [9]. Enhancement of carrier injection by several orders of magnitude has been demonstrated as a result of this procedure, and is attributable to the doping-induced lowering of the electrode-polymer holeinjection barrier. However, such a structure comprises by design a large dopant concentration gradient across the laminated interface, and the possibility of dopant diffusion from the laminated layer into the organic device needs to be considered. Neutral or ionized dopants can act as exciton quenchers in light-emitting and harvesting devices [19-21], and charge carriers contributed by dopants can degrade the on/off current ratio of an organic transistor when present in excessive concentration in the channel [11]. The stability of dopants with respect to diffusion in the host matrix is, therefore, critical to the efficiency, stability and lifetime of the device.

Extensive diffusion of dopants such as lithium (Li) or molybdenum tri-oxide $\left(\mathrm{MoO}_{3}\right)$ has been observed in various small-molecule 
films $[22,23]$, and attributed in part to their small size. The larger molecular p-dopant $\mathrm{F}_{4}$-TCNQ was found to diffuse in zinc phthalocyanine (ZnPc) [5] or 4,4'-bis(N-carbazolyl)-1,1'-biphenyl (CBP) [24], two partially crystalline materials, but to be spatially stable in $\quad \mathrm{N}, \mathrm{N}^{\prime}-\mathrm{di}-\left[\left(1\right.\right.$-naphthyl)-N, $\mathrm{N}^{\prime}$-diphenyl]-1,1'-biphenyl)-4,4'-diamine $(\alpha-N P D)$ [25], a typically amorphous material. Mo(tfd $)_{3}$ was also found to be stable in $\alpha$-NPD [15]. Both the size of the dopant and the structure of the organic semiconductor are therefore presumably important in terms of dopant spatial stability.

Studies of the distribution and stability of dopants in polymer films have been very sparse to date. We recently reported on the solution-based p-doping of P3HT with a new soluble dopant, molybdenum tris[1-(methoxycarbonyl)-2-(trifluoromethyl)-ethane-1,2dithiolene] $\left(\mathrm{Mo}\left(\mathrm{tfd}-\mathrm{CO}_{2} \mathrm{Me}\right)_{3}\right)$ [9]. Using soft-contact lamination of ultra-thin $(30 \mathrm{~nm})$ p-doped P3HT layers, we demonstrated significant enhancement of hole injection into undoped P3HT, as well as efficient hole collection from solution-processed bulk-heterojunction solar cells composed of P3HT and either 6,6-phenyl-C61-butyric acid methyl ester (PCBM) or P3HT:indene- $\mathrm{C}_{60}$ bis-adduct (ICBA). The present paper extends this work with an investigation of the diffusion of $\left(\mathrm{Mo}\left(\mathrm{tfd}-\mathrm{CO}_{2} \mathrm{Me}\right)_{3}\right)$ into pure P3HT and into the P3HT:ICBA blend active layer. Dopant diffusion is characterized via secondary ion mass spectrometry (SIMS) and current density-voltage $(J-V)$ measurements. Whereas the dopant is found to diffuse extensively in pure $\mathrm{P} 3 \mathrm{HT}$, it is found to be far more stable at the interface with the bulk-heterojunction blend.

\section{Experimental procedures}

The p-dopant $\mathrm{Mo}\left(\text { tfd- }-\mathrm{CO}_{2} \mathrm{Me}\right)_{3}$ was synthesized as reported elsewhere [9]. P3HT and ICBA were obtained from Merck Chemicals Ltd. and Sigma Aldrich, respectively, and used as received. P3HT was dissolved in chlorobenzene $\left(10-30 \mathrm{mg} \mathrm{mL}^{-1}\right.$ ) and stirred at $45{ }^{\circ} \mathrm{C}$ for $4 \mathrm{~h}$. $\mathrm{Mo}\left(\mathrm{tfd}-\mathrm{CO}_{2} \mathrm{Me}\right)_{3}$ was also dissolved in chlorobenzene $\left(2-4 \mathrm{mg} \mathrm{mL}^{-1}\right)$. The dopant concentration of $3.8 \mathrm{wt} \%$ used in this work was achieved by mixing appropriate amounts of the two solutions, followed by $10 \mathrm{~h}$ stirring at $45^{\circ} \mathrm{C}$. In the remainder of the paper, the doping concentration is given in wt\%, with the understanding that $1 \mathrm{wt} \%$ of $\mathrm{Mo}\left(\mathrm{tfd}-\mathrm{CO}_{2} \mathrm{Me}\right)_{3}$ in P3HT corresponds to one dopant molecule per $\sim 450$ P3HT monomers.

SIMS measurements were performed by the Evans Analytical Group (EAG). Samples were prepared in the Princeton laboratory, then transferred to EAG for SIMS measurements conducted after about a week. Samples were analyzed using Oxygen primary ion on a PHI 6600 model quadrupole analyzer SIMS instrument; conditions were optimized to give the best detection limit for measuring
Mo positive atomic ions. Samples used for SIMS analysis were deposited on Si substrates pre-cleaned by sequential sonication steps in acetone and isopropanol (15 min each). The samples had the following structures: (a) Si/3.8 wt\% doped P3HT (70 nm), (b) $\mathrm{Si} / 3.8 \mathrm{wt} \%$ doped P3HT(70 $\mathrm{nm}) / \mathrm{P} 3 \mathrm{HT}(80 \mathrm{~nm})$ and (c) $\mathrm{Si} /$ P3HT:ICBA (150 nm)/3.8 wt\% doped P3HT (30 nm)/P3HT:ICBA $(150 \mathrm{~nm})$ (Fig. 1). These multilayers were fabricated via soft-contact transfer lamination (SCTL) of the separately prepared undoped and doped layers. The details of the lamination procedure were introduced elsewhere [9]. Doped P3HT films in direct contact with the Si substrate were spin-coated in $\mathrm{N}_{2}$ from an appropriately mixed host-dopant co-solution (ca. $10-20 \mathrm{mg} \mathrm{mL}^{-1}$ in chlorobenzene) at $1500 \mathrm{rpm}$ for $40 \mathrm{~s}$, followed by annealing at $110^{\circ} \mathrm{C}$ for 10 min, giving ca. $30-100 \mathrm{~nm}$ thick films. Films prepared for SCTL were originally spin-coated on a UV-ozone treated Si surface with no subsequent annealing, then transferred to a PDMS stamp [9]. For bulk heterojunction (BHJ) films, P3HT and ICBA were mixed in 1,2 -dichlorobenzene with a $1: 1$ weight ratio $\left(40 \mathrm{mg} \mathrm{mL}^{-1}\right) . \mathrm{BHJ}$ films $(150 \mathrm{~nm})$ were formed by spin-coating at $1500 \mathrm{rpm}$ for $60 \mathrm{~s}$. The active layer was then solvent-annealed overnight, and then annealed on a hot plate at $160{ }^{\circ} \mathrm{C}$ for $10 \mathrm{~min}$ in $\mathrm{N}_{2}$, while the polymer layer (doped, undoped P3HT or bulk-heterojunction P3HT:ICBA blend) to be transferred via lamination was initially spun in $\mathrm{N}_{2}$ onto a UV-ozone exposed silicon substrate, with no subsequent annealing. The films were then taken out of the $\mathrm{N}_{2}$ environment for the SCTL lamination procedure. No post-fabrication annealing was performed on sample (c), while sample (b) were either not annealed or annealed at $100{ }^{\circ} \mathrm{C}$ for $10 \mathrm{~min}$ in $\mathrm{N}_{2}$.

The stability of dopants in P3HT was also investigated through electrical measurements on two types of structures: (Device A) ITO/PEDOT:PSS $4083(40 \mathrm{~nm}) / 3.8 \mathrm{wt} \%$ doped P3HT $(80 \mathrm{~nm}) / \mathrm{P} 3 \mathrm{HT}$ $(90 \mathrm{~nm}) / \mathrm{Ag}$ and (Device B) ITO/PEDOT:PSS $4083(40 \mathrm{~nm}) / \mathrm{P} 3 \mathrm{HT}$ $(90 \mathrm{~nm}) / 3.8 \mathrm{wt} \%$ doped P3HT $(80 \mathrm{~nm}) / \mathrm{Ag}$ (Fig. 4(b)). The ITO substrates were sequentially sonicated in Alconox ${ }^{\mathrm{R}}$, acetone, and isopropanol (15 min each), and UV-ozone treated for $30 \mathrm{~min}$. PEDOT:PSS was spin-coated at $5000 \mathrm{rpm}$ for $40 \mathrm{~s}$ to create a $40 \mathrm{~nm}$ film, and annealed at $150{ }^{\circ} \mathrm{C}$ for $5 \mathrm{~min}$ in $\mathrm{N}_{2}$. Arrays of $1 \mathrm{~mm}^{2}$ top $\mathrm{Ag}$ contacts were evaporated in a vacuum chamber through a shadow mask. To test for dopant stability at the interface with a bulk heterojunction, inverted solar cells were made with the following structure: ITO/PEIE (polyethylenimine ethoxylated)/ P3HT:ICBA $(200 \mathrm{~nm}) / 3.8 \mathrm{wt} \%$ P3HT $(30 \mathrm{~nm}) / \mathrm{Ag}$, with ITO/PEIE for electron collection at the bottom and doped P3HT laminated on the top for hole collection. The fabrication procedure was reported elsewhere [9]. Ag contacts were deposited through a shadow mask in a vacuum thermal evaporator (EvoVac, Angstrom Engineering Inc.) at a base pressure of $7 \times 10^{-7}$ Torr; the effective area of the

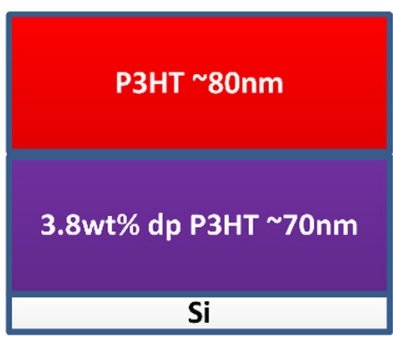

(b)
P3HT:ICBA 150nm

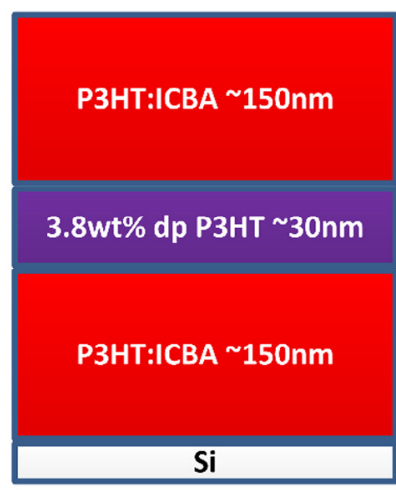

(c)

Fig. 1. Sample structures for SIMS analysis. 
device was $0.1 \mathrm{~cm}^{2}$. Current density-voltage $(J-V)$ characteristics of the solar cells were measured in $\mathrm{N}_{2}$ with a source meter (2602B, Keithley Instruments, Cleveland, OH) controlled by a LabVIEW program. A solar simulator with an air mass 1.5 filter and an intensity of $100 \mathrm{~mW} \mathrm{~cm}^{-2}$ (Sun 2000, ABET technologies) was used to measure device efficiencies.

\section{Results and discussion}

\subsection{Dopant distribution profile in uniformly doped P3HT}

A single layer of P3HT doped with $3.8 \mathrm{wt} \%$ of $\mathrm{Mo}\left(\mathrm{tfd}-\mathrm{CO}_{2} \mathrm{Me}\right)_{3}$ spin-coated on Si (Fig. 1(a)) was analyzed first. The C, Mo and Si signals extracted from the SIMS analysis are plotted in Fig. 2 as a function of depth from the surface. The abrupt rise in Si intensity ( $5 \mathrm{~nm} /$ decade) marks the P3HT/Si interface. To eliminate the confusing effect of $\mathrm{CO}$ mass interference giving a spurious "Si" signal in the polymer layer, the Si profile is plotted only from the Si interface into the substrate. The depth scale, confirmed via stylus profilometry, is set with the free surface of the film at $0 \mathrm{~nm}$ and the $\mathrm{P} 3 \mathrm{HT} / \mathrm{Si}$ interface at $60 \mathrm{~nm}$, in good agreement with the $\sim 70 \mathrm{~nm}$ obtained from AFM thickness measurement. The C intensity is constant across the film, as expected, and decreases as the sample erosion penetrates the Si. More importantly, the Mo concentration is found to be constant through doped P3HT film, indicating a uniform distribution of dopants without significant aggregation at the surface or at the interface. The Mo concentration within the doped P3HT film was calibrated independently with standard Rutherford backscattering (RBS) measurements performed by EAG, and found to be approximately $3.4 \mathrm{wt} \%$, in good agreement with the intended doping concentration of $3.8 \mathrm{wt} \%$. Note that the apparent rise in Mo and $\mathrm{C}$ signal at the $\mathrm{P} 3 \mathrm{HT} / \mathrm{Si}$ interface are profile distortion due to secondary ion yield change (matrix effect) between the polymer and Si [26]. The decrease and rise of the Mo signal at the P3HT surface are also artifacts associated with the start of the SIMS measurement.

\subsection{Dopant diffusion across P3HT interfaces}

Depth profiles of dopant concentration were then measured with SIMS across the bilayer structure built via SCTL (Fig. 1(b)). The $\mathrm{Si}$, Mo and $\mathrm{C}$ signals versus depth of the laminated bilayer structure $\mathrm{Si} / 3.8 \mathrm{wt} \%$ doped P3HT (70 nm)/P3HT $(80 \mathrm{~nm})$ are shown in Fig. 3. The rise in Si intensity ( $20 \mathrm{~nm} /$ decade) again marks the

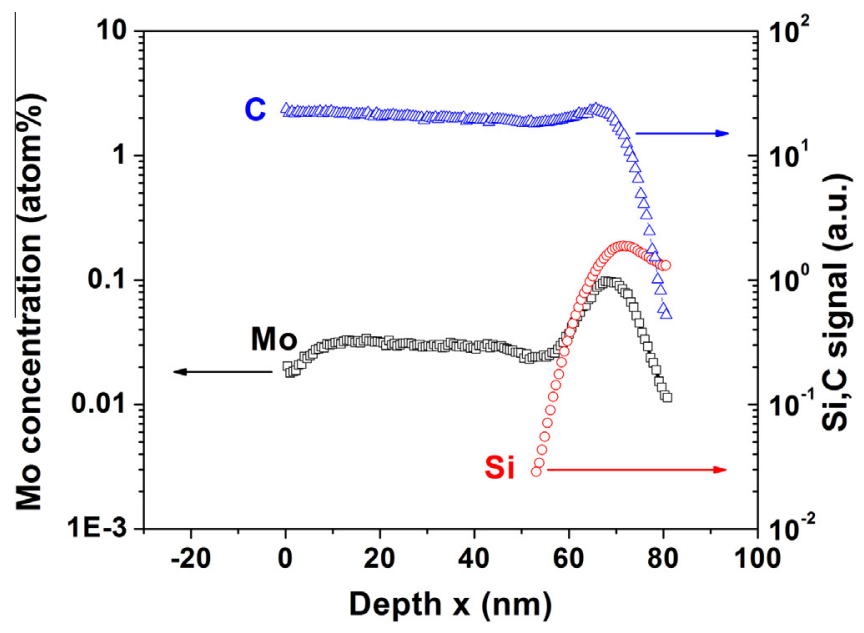

Fig. 2. SIMS profiles of C, Si signal and Mo concentration vs. depth for a 3.8 wt $\%$ doped P3HT film on Si (sample (a) of Fig. 1).

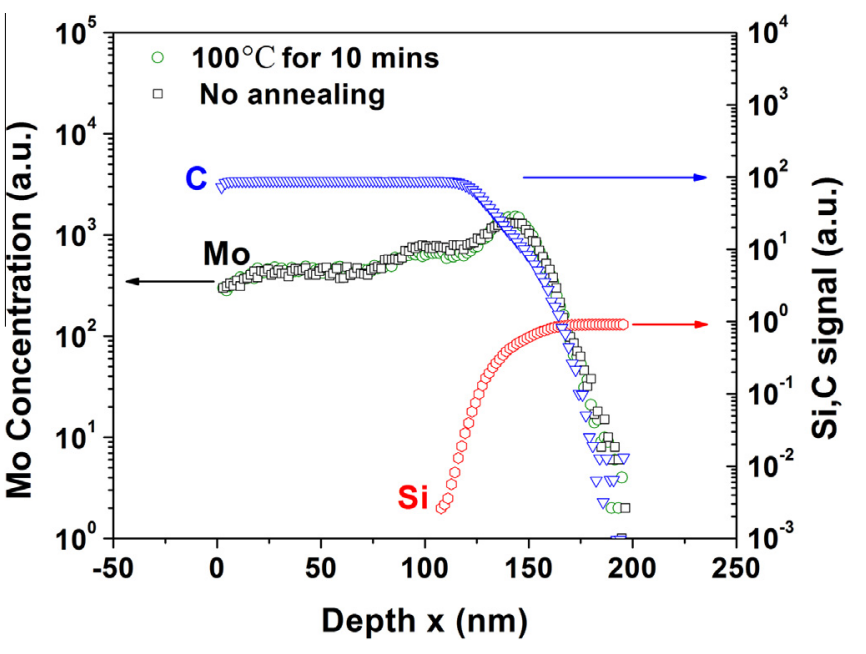

Fig. 3. SIMS profiles of C, Si signal and Mo concentration vs. depth for a $3.8 \mathrm{wt} \%$ doped P3HT/P3HT bilayer film on Si (sample (b) of Fig. 1), not annealed or annealed at $100{ }^{\circ} \mathrm{C}$ for $10 \mathrm{~min}$.

polymer/Si interface at about $125 \mathrm{~nm}$ below the P3HT surface, consistent with the estimate of $\sim 150 \mathrm{~nm}$ obtained from AFM measurement. The remarkable result is that the Mo concentration is found to be almost uniform across the bilayer films, with relatively little difference between the originally undoped pure P3HT (top $80 \mathrm{~nm}$ ) layer and the intentionally doped layer (bottom $70 \mathrm{~nm}$ in contact with $\mathrm{Si}$ ). The small concentration difference, i.e. less than a factor of 2, demonstrates the strong diffusion of dopants from the $3.8 \mathrm{wt} \%$ doped P3HT layer into the top layer, all the way to the surface of the undoped P3HT layer. Given that the total amount of dopant remains constant within the bilayer structure, the redistribution of $\mathrm{Mo}\left(\mathrm{tfd}-\mathrm{CO}_{2} \mathrm{Me}\right)_{3}$ molecules leads to dopant concentrations in the pure P3HT layer and the intentionally doped bottom layer of about $1.5 \mathrm{wt} \%$ and $2.3 \mathrm{wt} \%$, respectively. There is little $\mathrm{Mo}\left(\mathrm{tfd}-\mathrm{CO}_{2} \mathrm{Me}\right)_{3}$ concentration gradient in either layer, suggesting that the dopant distribution has reached a new equilibrium at room temperature. Indeed, when the same bilayer structure was annealed at $100{ }^{\circ} \mathrm{C}$ for $10 \mathrm{~min}$ in $\mathrm{N}_{2}$, very similar SIMS depth profiles were obtained, suggesting that post-fabrication annealing does not induce further diffusion of dopants through the assembly.

The impact of dopant diffusion was investigated via electrical measurement on bilayer structures. Room temperature current density-voltage $(J-V)$ measurements were performed under $\mathrm{N}_{2}$ on a series of hole-only diode structures consisting of either $\sim 160 \mathrm{~nm}$-thick single layers of undoped or doped P3HT, or laminated bilayers consisting of doped and undoped P3HT layers sandwiched between PEDOT:PSS (AI 4083) and a Ag contact (device structures shown in Fig. 4) We previously reported that $1 \mathrm{wt} \% \mathrm{Mo}\left(\mathrm{tfd}-\mathrm{CO}_{2} \mathrm{Me}\right)_{3}$ doping in P3HT already eliminates the difference between Ag and PEDOT:PSS contacts in terms of hole injection [9], and we chose these electrodes for $J-V$ measurements as sensitive indicators of the presence of dopants at the Ag/polymer interface. Bias is applied to the Ag contact while the ITO/ PEDOT:PSS substrate remains grounded. Given the PEDOT:PSS and $\mathrm{Ag}$ work functions ( $\sim 4.9 \mathrm{eV}$ and $4.5 \mathrm{eV}$ respectively) and the P3HT electron affinity (2.1 eV [27]), electron-injection barriers into P3HT are anticipated to be very high and, therefore, this process can be neglected. As shown in Fig. 4, the room temperature $J-V$ curve of the undoped P3HT single-layer devices is asymmetric, reflecting considerably stronger hole injection on the PEDOT:PSS side.

Different $J-V$ characteristics were expected for devices A and B (Fig. 4). In device A, a laminated doped P3HT interlayer is inserted 


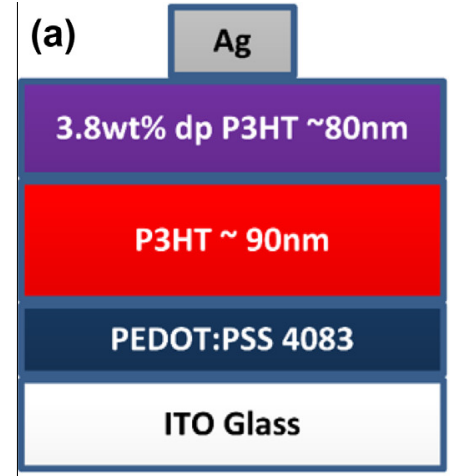

Device A

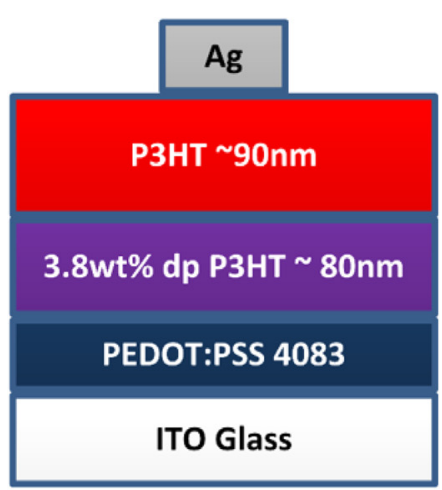

Device B

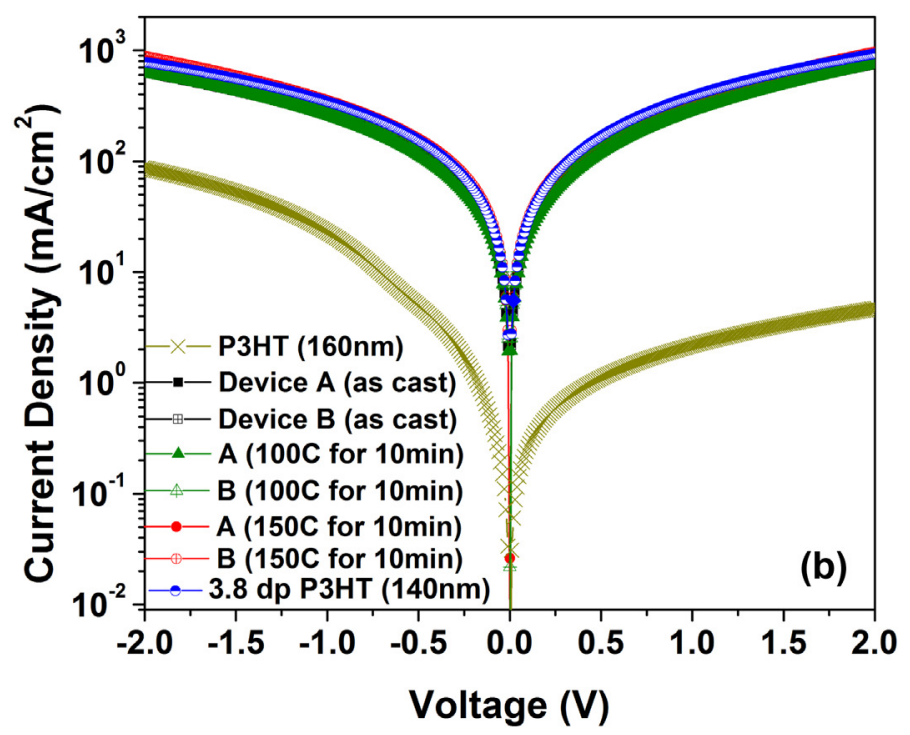

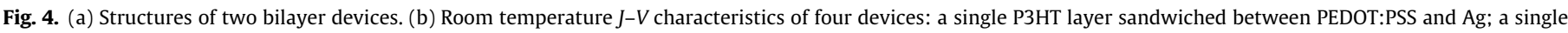
3.8 wt\% doped P3HT layer sandwiched between PEDOT:PSS and Ag; and devices A and B following various annealing sequences.

on the Ag side, lowering the effective injection barrier for this contact and leading, in principle, to more symmetric $J-V$ characteristics. In device $\mathrm{B}, \mathrm{Ag}$ is in contact with nominally undoped $\mathrm{P} 3 \mathrm{HT}$, leading in principle to more asymmetric $J-V$ characteristics. Yet, both laminated devices show symmetric and almost overlapping $J-V$ characteristics at room temperature, comparable to the intentionally doped single layer device (Fig. 4). We have previously demonstrated with P3HT that the soft contact lamination process leads to interfaces that are electronically and electrically seamless [28]. The evolution of the $J-V$ characteristics observed in Fig. 4 is therefore not a result of the lamination process, but rather of the presence of a significant density of dopants in the nominally undoped film under the Ag electrode in device $\mathrm{B}$, confirming the strong diffusion of dopants across the laminated interface (likely to occur in both devices). The injection barrier at the $\mathrm{Ag}$ contact in device $\mathrm{B}$ is reduced by the presence of dopants, leading to the symmetric $J-V$ characteristics.

The two bilayer structures were also annealed at $100{ }^{\circ} \mathrm{C}$ or $150{ }^{\circ} \mathrm{C}$ for $10 \mathrm{~min}$ under $\mathrm{N}_{2}$ prior to $\mathrm{Ag}$ contact deposition, and $J-V$ measurements were performed immediately after contact deposition (about $7 \mathrm{~h}$ after the lamination process). $J-V$ characteristics of the annealed devices (Fig. 4) show no significant difference with those of the non-annealed ones, suggesting that the annealing step does not contribute to further redistribution the dopants, consistent with the conclusions drawn from the SIMS measurements.

In summary, the diffusion of the $\mathrm{Mo}\left(\mathrm{tfd}-\mathrm{CO}_{2} \mathrm{Me}\right)_{3}$ dopant molecules through pure P3HT layers is extensive, even at room temperature. This phenomenon is reminiscent of the strong diffusion of PCBM in P3HT observed on a P3HT/PCBM bilayer by Treat et al. $[29,30]$. The diffusion of dopants occurs presumably through the disordered regions of the P3HT matrix and along the grain boundaries between crystalline P3HT domains.

\subsection{Dopant diffusion into P3HT:ICBA blends}

Laminated p-doped P3HT interlayers have been shown to form efficient hole-collection electrodes for bulk heterojunction $(\mathrm{BHJ})$ polymer solar cells [9]. Dopant diffusion into a P3HT-based blend active layer, as compared to a pure P3HT layer, is, therefore, of great interest. We investigate here the diffusion of $\mathrm{Mo}(\mathrm{tfd}-$ $\left.\mathrm{CO}_{2} \mathrm{Me}\right)_{3}$ into a P3HT:ICBA BHJ by fabricating a P3HT:ICBA/doped P3HT/P3HT:ICBA tri-layer sandwich structure via SCLT (Fig. 1(c)). The positioning of the doped layer between two undoped BHJs allows the evaluation of the dopant profile measured by SIMS when sputtering the sample from undoped to doped region, and vice versa. The SIMS profiles of the Mo concentration versus depth in the tri-layer structure are shown in Fig. 5. As previously noted, the abrupt rise in Si intensity ( $\sim 10 \mathrm{~nm} /$ decade) marks the polymer/Si interface at about $320 \mathrm{~nm}$ below the P3HT:ICBA surface, in good agreement with the intended total thickness of the tri-layer.

The steep rise of the Mo signal at the $125 \mathrm{~nm}$ mark $(\sim 10 \mathrm{~nm} /$ decade) as SIMS erosion crosses from the top P3HT:ICBA layer into 


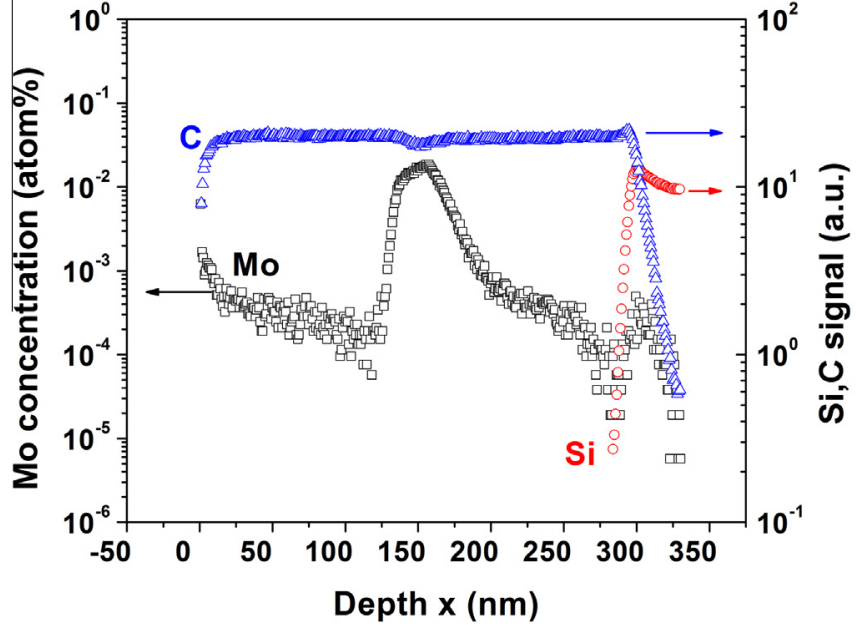

Fig. 5. SIMS profiles of C, Si signal and Mo concentration vs. depth for a P3HT:ICBA/ 3.8 wt\% doped P3HT/P3HT:ICBA trilayer sandwich structure on Si (sample (c) of Fig. 1).

the doped P3HT layer indicates an abrupt change in dopant concentration between the two layers, which is a significant departure from the case of sample (b) (Figs. 1 and 3). The Mo signal was calibrated in the system and the $\mathrm{Mo}\left(\mathrm{tfd}-\mathrm{CO}_{2} \mathrm{Me}\right)_{3}$ concentration in the intentionally doped middle layer is approximately $3.8 \mathrm{wt} \%$, while the Mo signal is at detection limit in the top P3HT:ICBA layer (two orders of magnitude lower than in the doped layer). This abrupt transition across the laminated interface indicates a far lower level of diffusion of $\mathrm{Mo}\left(\mathrm{tfd}-\mathrm{CO}_{2} \mathrm{Me}\right)_{3}$ into the blend layer, as compared to the pure P3HT layer.

The Mo profile at the bottom P3HT/P3HT:ICBA heterojunction shows a somewhat broader tail into the blend layer. Yet, this profile is unlikely to correspond to stronger dopant diffusion into the bottom layer than in the top layer. It is attributed to SIMS measurement artifacts such as the knock-on effect [31] or sputteringinduced chemical segregation [32]. Organic semiconductors are rich in carbon; as oxygen ions are used to sputter the sample surface, CO groups could form and lead to an acceleration of the sputtering rate of carbon, while leaving heavier elements, such as Mo, behind. Hence, the front side of the SIMS profile is more convincing in revealing the level of diffusion of the dopants into the P3HT:ICBA blend layer.

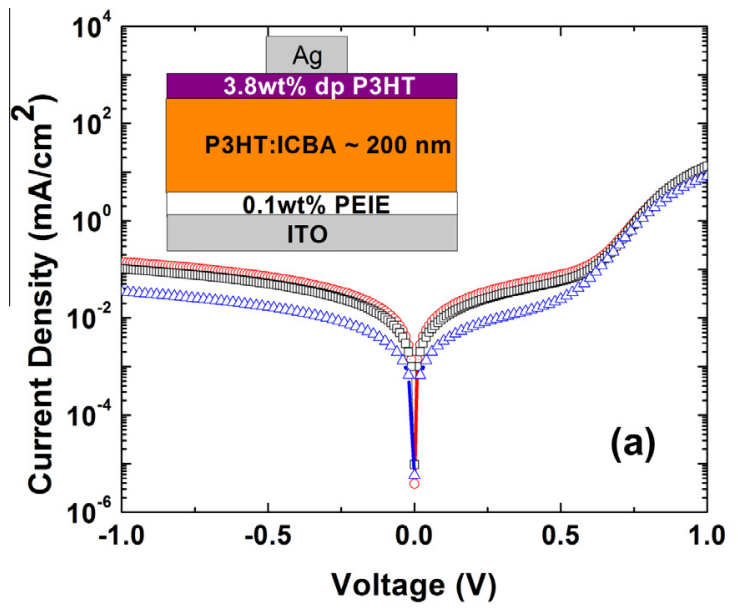

\subsection{Stability of solar cells with laminated doped P3HT interlayer}

Finally, the stability of complete solar cells with p-doped P3HT hole-extraction layer fabricated via SCTL was investigated. $J-V$ characteristics were recorded before and after a $50{ }^{\circ} \mathrm{C}, 1 \mathrm{~h}$ anneal in $\mathrm{N}_{2}$, as well as after an 80-day period of shelf storage in $\mathrm{N}_{2}$ without encapsulation. The $J-V$ characteristics in the dark and under illumination recorded at these three different times are shown in Fig. 6, and performances are summarized in Table 1 . The $1 \mathrm{~h}$ anneal does not change appreciably the fill factor nor $V_{\mathrm{oc}}$, and slightly increases the short-circuit current, confirming the absence of significant dopant diffusion into the active layer over this period of time and at elevated temperature. Indeed, dopants are potential exciton quencher and diffusion of $\mathrm{Mo}\left(\mathrm{tfd}-\mathrm{CO}_{2} \mathrm{Me}\right)_{3}$ molecules into the active layer would be expected to degrade the solar cell performance. Devices kept in a $\mathrm{N}_{2}$-filled glove box for 80 days also show promising stability, with less than $10 \%$ decrease in efficiency, mainly due to a slight change in fill factor.

Finally, the stability of the dopant was also tested under electrical stress. In order to evaluate the motion of ionized dopants due to a field in the device, we stressed the solar cells electrically by applying a constant voltage $V_{s}$, interrupting every $1 \mathrm{~h}$ to immediately measure the characteristics of the cell. The $J-V$ curves under illumination recorded for different stress voltages are shown in Fig. 7. The excellent overlap of the data demonstrate that the performance of the solar cell is independent of the magnitude and sign of the stress voltage, and consistent with the absence of field-induced penetration of dopant into the active layer.

Electrical characteristics of electronic devices, organic solar cells in particular, are highly sensitive to changes in morphology or electronic structure of the device constituents, and to the presence of defects and recombination centers in the active layer. In the present case, the lack of degradation of the $J-V$ characteristics provides confirmation of the SIMS measurements of the absence of dopant diffusion into the P3HT:ICBA BHJ layer, in stark contract with the situation encountered with the pure P3HT layer. The blend layer presumably consists of crystalline P3HT domains and more disordered areas of the polymer mixed with the fullerene-based acceptor. ICBA presumably fills vacant sites in the more disordered phases, effectively eliminating the paths that lead to strong dopant diffusion into the pure polymer layer. Spatially confined interface doping via SCTL becomes therefore a viable solution for fabricating efficient contacts on P3HT-based BHJ solar cells.

As mentioned above, previous investigations have shown extensive diffusion of the molecule $\mathrm{F}_{4}$-TCNQ in polycrystalline films of $\mathrm{ZnPc}$ [5] and CBP [24], in which the dopant moves

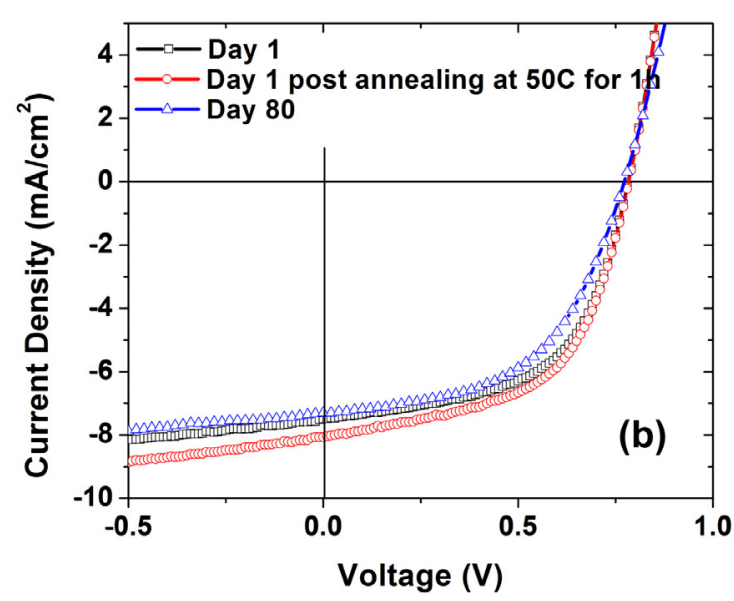

Fig. 6. $J-V$ characteristics of the P3HT:ICBA solar cell shown in inset, (a) in the dark, and (b) under AM1.5 illumination (100 $\left.\mathrm{mW} / \mathrm{cm}^{2}\right)$. 
Table 1

Solar cell performance.

\begin{tabular}{lllll}
\hline Condition & $V_{\text {oc }}(\mathrm{V})$ & $J_{\mathrm{sc}}\left(\mathrm{mA} / \mathrm{cm}^{2}\right)$ & FF & Efficiency $(\%)$ \\
\hline Day 1 as cast & 0.78 & 7.5 & 0.57 & 3.33 \\
Day 1 post annealing & 0.78 & 8.05 & 0.56 & 3.53 \\
Day 80 & 0.78 & 7.3 & 0.52 & 2.99 \\
\hline
\end{tabular}

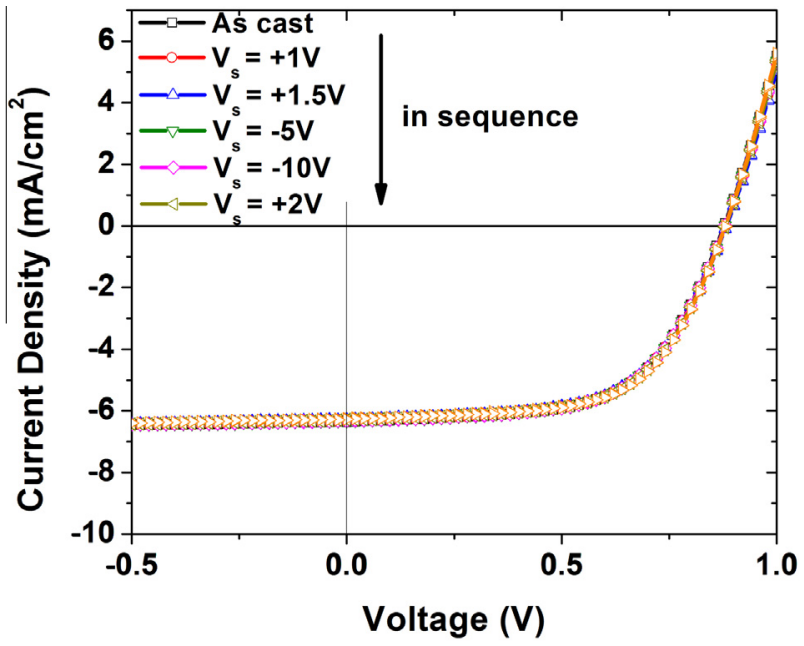

Fig. 7. $J-V$ characteristics of a P3HT:ICBA solar cell (same structure as in Fig. 6) under AM1.5 illumination $\left(100 \mathrm{~mW} / \mathrm{cm}^{2}\right)$, measured immediately following subsequent electric stress periods of $1 \mathrm{~h}$, at stress voltage $V_{s}$. A positive (negative) $V_{s}$ represents a positive (negative) bias on the Ag contact.

preferentially along grain boundaries, while little diffusion was seen in the amorphous matrix of $\alpha$-NPD [25]. In the present case, we assume that $\mathrm{Mo}\left(\mathrm{tfd}-\mathrm{CO}_{2} \mathrm{Me}\right)_{3}$ preferentially moves along the disordered areas/grain boundaries of the pure P3HT matrix, while these paths are all but eliminated by the fullerene-based acceptor in the bulk heterostructure. Investigations to further test this hypothesis on more amorphous pure polymers are currently under way.

\section{Conclusions}

We have used SIMS and electrical measurements on laminated doped layers to demonstrate that the three-dimensional molecular p-dopant $\mathrm{Mo}\left(\mathrm{tfd}-\mathrm{CO}_{2} \mathrm{Me}\right)_{3}$ diffuses extensively at room temperature in pure P3HT films. However, diffusion is all but eliminated in P3HT-based bulk heterostructures, in which fullerene acceptors (ICBA) presumably block the diffusion path. The stability of these laminated doped P3HT/P3HT:ICBA structures opens another promising route to achieving all-solution processible devices with efficient injection/extraction barriers.

\section{Acknowledgments}

Support of this work at Princeton was through the Princeton MRSEC of the National Science Foundation (DMR-0819860) and a Grant of the National Science Foundation (DMR-1005892). Work at the Georgia Institute of Technology was supported in part by the Center for Interface Science: Solar-Electric Materials (CIS:SEM), an Energy Frontier Research Center funded through the U.S. Department of Energy, Office of Basic Energy Sciences, under Award No. DE-SC0001084 (for development of procedures for efficient synthesis of dopants), and by the Office of Naval Research (N00014-11-1-0313, for the initial studies on the development of the $\mathrm{Mo}\left(\mathrm{tfd}-\mathrm{CO}_{2} \mathrm{Me}\right)_{3}$ dopant used in this paper). The authors are grateful to Dr. Taewook Koh and Prof. Barry Rand for help with solar cell fabrication.

\section{References}

[1] J. Kido, T. Matsumoto, Bright organic electroluminescent devices having a metal-doped electron-injecting layer, Appl. Phys. Lett. 73 (1998) 2866, http:// dx.doi.org/10.1063/1.122612.

[2] C. Ganzorig, M. Fujihira, A lithium carboxylate ultrathin film on an aluminum cathode for enhanced electron injection in organic electroluminescent devices, Jpn. J. Appl. Phys. 38 (1999) L1348. http://stacks.iop.org/1347-4065/38/i=11B/ $\mathrm{a}=\mathrm{L} 1348$.

[3] B. Maennig, M. Pfeiffer, A. Nollau, X. Zhou, K. Leo, P. Simon, Controlled p-type doping of polycrystalline and amorphous organic layers: self-consistent description of conductivity and field-effect mobility by a microscopic percolation model, Phys. Rev. B 64 (2001) 195208, http://dx.doi.org/10.1103/ PhysRevB.64.195208.

[4] J. Blochwitz, T. Fritz, M. Pfeiffer, K. Leo, D.M. Alloway, P.A. Lee, et al., Interface electronic structure of organic semiconductors with controlled doping levels, Org. Electron. 2 (2001) 97-104, http://dx.doi.org/10.1016/S15661199(01)00016-7.

[5] W. Gao, A. Kahn, Controlled p-doping of zinc phthalocyanine by coevaporation with tetrafluorotetracyanoquinodimethane: a direct and inverse photoemission study, Appl. Phys. Lett. 79 (2001) 4040, http://dx.doi.org/ 10.1063/1.1424067.

[6] S. Olthof, S. Mehraeen, S.K. Mohapatra, S. Barlow, V. Coropceanu, J.-L. Brédas, et al., Ultralow doping in organic semiconductors: evidence of trap filling. Phys. Rev. Lett. 109 (2012) 176601, http://dx.doi.org/10.1103/PhysRevLett. 109.176601.

[7] J. Blochwitz, M. Pfeiffer, T. Fritz, K. Leo, Low voltage organic light emitting diodes featuring doped phthalocyanine as hole transport material, Appl. Phys. Lett. 73 (1998) 729, http://dx.doi.org/10.1063/1.121982.

[8] C.K. Chan, W. Zhao, A. Kahn, I.G. Hill, Influence of chemical doping on the performance of organic photovoltaic cells, Appl. Phys. Lett. 94 (2009) 203306, http://dx.doi.org/10.1063/1.3138131.

[9] A. Dai, Y. Zhou, A.L. Shu, S.K. Mohapatra, H. Wang, C. Fuentes-Hernandez, et al., Enhanced charge-carrier injection and collection via lamination of doped polymer layers p-doped with a solution-processible molybdenum complex Adv. Funct. Mater. 24 (2014) 2197-2204, http://dx.doi.org/10.1002/ adfm.201303232.

[10] G. He, M. Pfeiffer, K. Leo, M. Hofmann, J. Birnstock, R. Pudzich, et al., Highefficiency and low-voltage p-i-n electrophosphorescent organic light-emitting diodes with double-emission layers, Appl. Phys. Lett. 85 (2004) 3911, http:// dx.doi.org/10.1063/1.1812378.

[11] S. Olthof, S. Singh, S.K. Mohapatra, S. Barlow, S.R. Marder, B. Kippelen, et al. Passivation of trap states in unpurified and purified C60 and the influence on organic field-effect transistor performance, Appl. Phys. Lett. 101 (2012) 253303, http://dx.doi.org/10.1063/1.4772551.

[12] C.J. Bloom, C.M. Elliott, P.G. Schroeder, C.B. France, B.A. Parkinson, Low work function reduced metal complexes as cathodes in organic electroluminescent devices, J. Phys. Chem. B 107 (2003) 2933-2938, http://dx.doi.org/10.1021/ jp026865b.

[13] C.K. Chan, W. Zhao, S. Barlow, S. Marder, A. Kahn, Decamethylcobaltocene as an efficient n-dopant in organic electronic materials and devices, Org. Electron. 9 (2008) 575-581, http://dx.doi.org/10.1016/j.orgel.2008.03.003.

[14] M. Kröger, S. Hamwi, J. Meyer, T. Riedl, W. Kowalsky, A. Kahn, P-type doping of organic wide band gap materials by transition metal oxides: a case-study on molybdenum trioxide, Org. Electron. 10 (2009) 932-938, http://dx.doi.org/ 10.1016/j.orgel.2009.05.007.

[15] Y. Qi, T. Sajoto, M. Kröger, A.M. Kandabarow, W. Park, S. Barlow, et al., A molybdenum dithiolene complex as p -dopant for hole-transport materials: a multitechnique experimental and theoretical investigation, Chem. Mater. 22 (2010) 524-531, http://dx.doi.org/10.1021/cm9031623.

[16] S. Guo, S.B. Kim, S.K. Mohapatra, Y. Qi, T. Sajoto, A. Kahn, et al., n-Doping of organic electronic materials using air-stable organometallics, Adv. Mater. 24 (2012) 699-703, http://dx.doi.org/10.1002/adma.201103238.

[17] Y. Qi, S.K. Mohapatra, S. Bok Kim, S. Barlow, S.R. Marder, A. Kahn, Solution doping of organic semiconductors using air-stable n-dopants, Appl. Phys. Lett 100 (2012) 083305, http://dx.doi.org/10.1063/1.3689760.

[18] K. Harada, A. Werner, M. Pfeiffer, C. Bloom, C. Elliott, K. Leo, Organic homojunction diodes with a high built-in potential: interpretation of the current-voltage characteristics by a generalized einstein relation, Phys. Rev. Lett. 94 (2005) 036601, http://dx.doi.org/10.1103/PhysRevLett. 94.036601.

[19] V. Arkhipov, E. Emelianova, H. Bässler, Quenching of excitons in doped disordered organic semiconductors, Phys. Rev. B 70 (2004) 205205, http:// dx.doi.org/10.1103/PhysRevB.70.205205.

[20] V.I. Arkhipov, E.V. Emelianova, H. Bässler, On the role of spectral diffusion of excitons in sensitized photoconduction in conjugated polymers, Chem. Phys. Lett. 383 (2004) 166-170, http://dx.doi.org/10.1016/j.cplett.2003.11.008.

[21] A.J. Ferguson, N. Kopidakis, S.E. Shaheen, G. Rumbles, Quenching of excitons by holes in poly(3-hexylthiophene) films, J. Phys. Chem. C 112 (2008) 9865-9871, http://dx.doi.org/10.1021/jp7113412.

[22] Y. Zhao, J. Zhang, S. Liu, Y. Gao, X. Yang, K.S. Leck, et al., Transition metal oxides on organic semiconductors, Org. Electron. 15 (2014) 871-877, http:// dx.doi.org/10.1016/j.orgel.2014.01.011.

[23] G. Parthasarathy, C. Shen, A. Kahn, S.R. Forrest, Lithium doping of semiconducting organic charge transport materials, J. Appl. Phys. 89 (2001) 4986, http://dx.doi.org/10.1063/1.1359161. 
[24] J. Xue, S. Forrest, Bipolar doping between a molecular organic donor-acceptor couple, Phys. Rev. B 69 (2004) 245322, http://dx.doi.org/10.1103/ PhysRevB.69.245322.

[25] W. Gao, A. Kahn, Controlled p doping of the hole-transport molecular material $\mathrm{N}, \mathrm{N}^{\prime}$-diphenyl-N,N'-bis(1-naphthyl)-1,1'-biphenyl-4,4'-diamine

with tetrafluorotetracyanoquinodimethane, J. Appl. Phys. 94 (2003) 359, http:// dx.doi.org/10.1063/1.1577400.

[26] R.G. Wilson, F.A. Stevie, C.W. Magee, Secondary Ion Mass: Profiling and Bulk Impurity Analysis, John Wiley Sons, New York, 1989 (section 2.3).

[27] Z.-L. Guan, J.B. Kim, H. Wang, C. Jaye, D.A. Fischer, Y.-L. Loo, et al., Direct determination of the electronic structure of the poly(3hexylthiophene):phenyl-[6,6]-C61 butyric acid methyl ester blend, Org. Electron. 11 (2010) 1779-1785, http://dx.doi.org/10.1016/j.orgel.2010.07.023.

[28] A.L. Shu, A. Dai, H. Wang, Y.-L. Loo, A. Kahn, Electronic structure and carrier transport at laminated polymer homojunctions, Org. Electron. 14 (2013) 149155, http://dx.doi.org/10.1016/j.orgel.2012.09.023.
[29] N.D. Treat, T.E. Mates, C.J. Hawker, E.J. Kramer, M.L. Chabinyc, Temperature dependence of the diffusion coefficient of PCBM in poly(3-hexylthiophene), Macromolecules 46 (2013) 1002-1007, http://dx.doi.org/10.1021/ ma302337p.

[30] N.D. Treat, M.A. Brady, G. Smith, M.F. Toney, E.J. Kramer, C.J. Hawker, et al., Interdiffusion of PCBM and P3HT reveals miscibility in a photovoltaically active blend, Adv. Energy Mater. 1 (2011) 82-89, http://dx.doi.org/10.1002/ aenm.201000023.

[31] F. Schulz, K. Wittmaack, J. Maul, Implications in the use of secondary ion mass spectrometry to investigate impurity concentration profiles in solids, Radiat. Eff. 18 (1973) 211-215, http://dx.doi.org/10.1080/00337577308232124.

[32] S. Hofmann, Compositional depth profiling by sputtering, Prog. Surf. Sci. 36 (1991) 35-87, http://dx.doi.org/10.1016/0079-6816(91)90013-T. 